\title{
CINA DAN VIETNAM: KETIADAAN KONFLIK TERBUKA DI LAUT CINA SELATAN
}

\author{
Bambang Waluyo
}

\begin{abstract}
Abstrak
Konflik yang terjadi di Laut Cina Selatan telah terjadi begitu lama dan melibatkan banyak negara termasuk di dalamnya Cina dan Vietnam. Masing-masing negara telah mengamankan klaim wilayahnya dengan militer namun konflik mengenai klaim tersebut belum mengakibatkan terjadinya konflik terbuka atau perang. Dengan menggunakan pertanyaan penelitian Mengapa tidak terjadi perang dalam konflik Laut Cina Selatan dengan konsep geopolitik milik Emmers, konflik terbuka di Laut Cina Selatan tidak terjadi karena pengaruh buruk terhadap stabilitas kawasan serta bagi negara yang memulainya. Memulai konflik terbuka dalam konflik antara Cina dan Vietnam di Laut Cina Selatan akan berdampak pada arah geopolitik kawasan.
\end{abstract}

Kata Kunci: Konflik Terbuka Laut Cina Selatan, Laut Cina Selatan, Vietnam, Cina.

\section{Pendahuluan}

Tulisan ini membahas mengenai konflik yang terjadi di Laut Cina Selatan yang melibatkan klaim atas berbagai negara seperti Cina, Taiwan, Brunei, Malaysia, Vietnam, dan Filipina. Dengan menggunakan pertanyaan penelitian "Mengapa tidak terjadi perang dalam konflik Laut Cina Selatan?". Pembahasan ini menjadi menarik karena perselisihan di antara negara-negara tersebut mengenai klaim wilayah perairan yang luas, meskipun masing-masing negara telah mengamankan klaim wilayahnya dengan militer namun konflik mengenai klaim tersebut belum mengakibatkan terjadinya konflik terbuka atau perang. Oleh karena itu, tulisan ini mencoba menjawab alasan dibalik ketidak adaan perang dalam konflik

di

Laut

Cina

Selatan. 
Laut Cina Selatan merupakan kawasan perairan yang berbatasan langsung dengan Republik Rakyat Cina serta negara-negara ASEAN. Kawasan perairan Laut Cina Selatan adalah sebuah wilayah strategis karena merupakan jalur perdagangan ekspor-impor dan jalur perdagangannya mencapai nilai yang sangat tinggi. Selain itu, Laut Cina Selatan mengandung gas alam dan kaya akan ikan sehingga nilai strategisnya pun bertambah. Sengketa Laut Cina Selatan melibatkan klaim pulau, karang dan maritim di antara beberapa negara berdaulat di wilayah tersebut. Seperti yang di sebutkan oleh Malczewsk dalam tulisannya Chinese Claim to the South China Sea under International Law (Klaudia Malczewska, n.d.), Klaim tersebut bermula dari klaim oleh Republik Rakyat Cina, kemudian Republik Rakyat Cina (RRC), yang meliputi sebagian besar Laut Cina Selatan dan tumpang tindih dengan klaim zona ekonomi eksklusif Brunei, Indonesia, Malaysia, Filipina, Taiwan, dan Vietnam.

Klaim tersebut meliputi batas laut di sepanjang pantai Vietnam antara RRC, Taiwan, dan Vietnam. Selain itu juga batas maritim utara Kalimantan antara RRC, Malaysia, Brunei, Filipina, dan Taiwan. Kemudian juga kepulauan, terumbu karang, tepi sungai, dan wilayah dangkal di Laut Cina Selatan, termasuk Kepulauan Paracel, Kepulauan Pratas dan Kepulauan Spratly antara RRC, Taiwan, dan Vietnam, dan sebagian wilayah itu juga diperebutkan oleh Malaysia dan Filipina. Batas laut di perairan utara Kepulauan Natuna antara RRC, Indonesia dan Taiwan hingga batas laut di lepas pantai Palawan dan Luzon antara RRC, Filipina, dan Taiwan tidak luput dari klaim tersebut, juga batas laut dan pulau-pulau di Selat Luzon antara RRC, Filipina, dan Taiwan.

Dalam kurun waktu satu dekade terakhir, terdapat sebuah masalah penting yang menjadi persoalan bagi stabilitas keamanan di Asia Tenggara sekaligus bagi kedaulatan nasional Indonesia. Masalah ini sering disebut sebagai "Sengketa Laut Cina Selatan". Sengketa Laut Cina Selatan 
merupakan buntut dari Claimant State dan pembuatan sembilan garis putus-putus (nine-dashed line) secara sepihak oleh Republik Rakyat Cina sejak periode 1950-an oleh rezim Mao Zedong (Purwantoro, 2020). Ninedashed line merupakan garis demarkasi atau garis batas pemisah yang digunakan pemerintah Republik Rakyat Cina untuk mengklaim sebagian besar wilayah Laut Cina Selatan (Lumbanrau R.E, 2016). Garis ini kemudian yang menimbulkan sengketa dengan sejumlah negara di Asia Tenggara. Sementara itu, Claimant State merupakan klaim atas kepemilikan pulau-pulau kecil di wilayah Laut Cina Selatan oleh Republik Rakyat Cina, seperti Kepulauan Spratly dan Paracel yang diperebutkan dengan Vietnam, Malaysia, dan Filipina.

Gambar 1.1 Nine-dashed line yang dibuat Cina memicu persoalan dengan

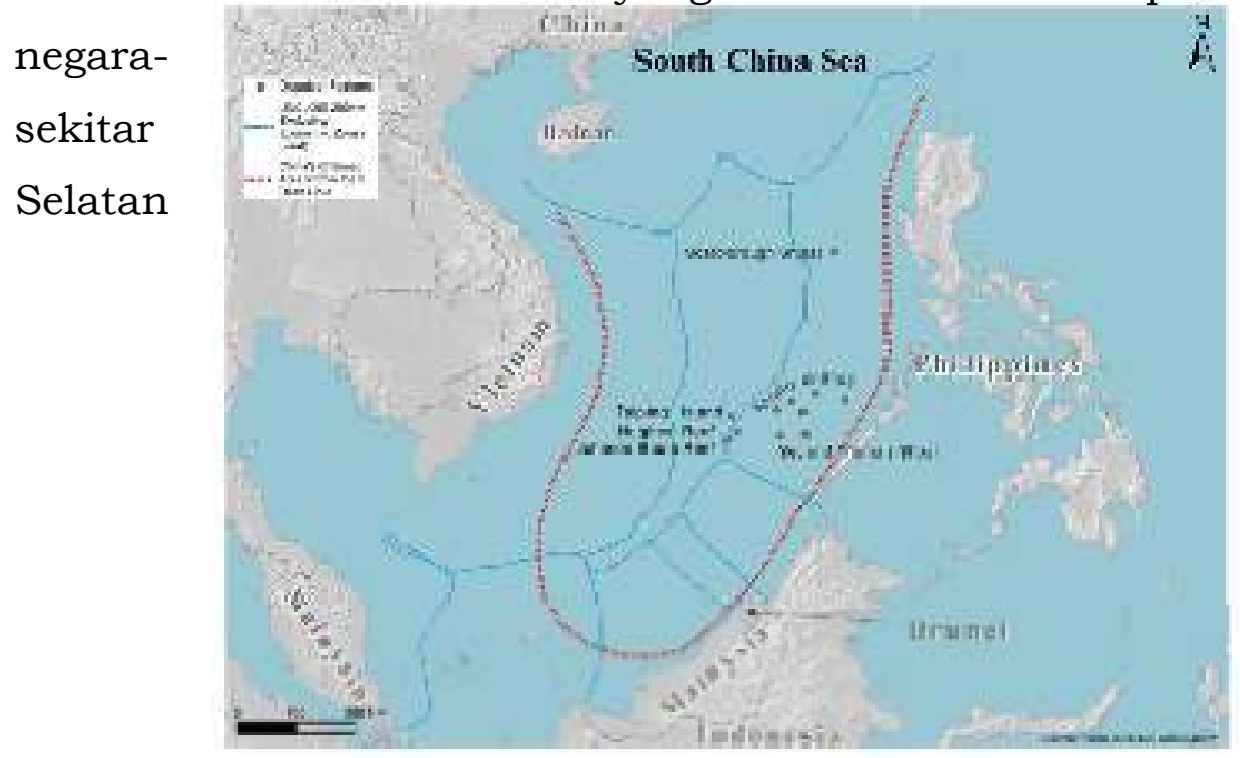

negara di

Laut Cina

Sumber : https://sites.tufts.edu/lawofthesea/chapter-ten/)

Mengenai nine-dashed line, hal yang menimbulkan sengketa adalah klaim sepihak Republik Rakyat Cina garis putus-putus (Gambar 1.1) yang bergesekan dengan batas beberapa negara di Asia Tenggara, yaitu Vietnam, Malaysia, Filipina, Indonesia, dan Brunei Darussalam. Klaim Cina tersebut berakibat pada berkurangnya luas laut negara-negara lain, 
seperti Filipina dan Malaysia, berkurang 80\%, Vietnam 50\%, dan Brunei 90\% (Mangkuto W.S, 2020). Adapun yang menjadi dasar dari nine-dashed line buatan Republik Rakyat Cina adalah alasan historis, dimana Republik Rakyat Cina beranggapan bahwa nine-dashed line merupakan wilayah milik mereka sejak zaman dahulu. Hal ini tentu bertentangan dengan UNCLOS 1982 yang tidak menyertakan klaim historis sebagai dasar kepemilikan wilayah atau teritorial (Cina kembali tegaskan klaim atas wilayah di Laut Cina Selatan, 2016). Cina telah menjadi pihak paling agresif dalam melakukan eksplorasi di Laut Cina Selatan serta terus membangun banyak fasilitas dan infrastruktur di wilayah di sepanjang nine-dashed line yang diklaim oleh Cina sebagai milik sendiri berdasarkan sejarahnya (Prawira, 2019).

Tulisan-tulisan terdahulu yang melakukan pembahasan mengenai hubungan Vietnam dan Cina dalam konflik di Laut Cina Selatan penulis kategorikan kedalam 2 kategori. Kategori yang pertama adalah penyelesaian konflik perbatasan seperti tulisan Ramses Amer (2014) dan Nguyen Hong Thao (2001). Kedua tulisan tersebut berfokus pada manajemen konflik antara Vietnam dan Cina di wilayah Laut Cina Selatan. kedua tulisan tersebut juga berfokus tentang pentingnya code of conduct yang saling disepakati oleh kedua pihak serta pentingnya keterlibatan organisasi internasional seperti ASEAN dalam upaya mencapai penyelesaian konflik. Pada kategori yang kedua adalah kerjasama internasional seperti tulisan milik Hai Dang Vu (2013) dan Shoji Tomotaka (2011). Pada kategori kedua, tulisan-tulisan tersebut berfokus pada bentuk bentuk kerjasama yang dilakukan antara negara yang berkonflik seperti Vietnam dan Cina dengan mengesampingkan permasalahan perbatasan yang terjadi di Laut Cina Selatan. Meskipun Cina secara cukup agresif melakukan pergerakan militer di wilayah Laut Cina Selatan, Vietnam merespon hal tersebut dengan melakukan perundingan bersama di ASEAN serta tetap melakukan kerjasama lain 
secara regional maupun bilateral bersama Cina dalam hal ekonomi serta kerjasama lain yang saling menguntungkan. Berdasarkan penelitianpenelitian sebelumnya, tulisan ini ingin menjelaskan bagaimana bisa terjadi kerjasama ekonomi dalam konflik perbatasan yang seharusnya menjadi kunci kedaulatan serta keamanan internasional.

Dengan menggunakan konsep geopolitik milik Ralf Emmers (2010) dalam salah satu bukunya yang berjudul Geopolitics and Maritime Territorial Disputes in East Asia, tulisan ini mencoba mengisi celah yang belum terjawab dari penelitian penelitian sebelumnya. Emmers berasumsi bahwa teritori, sumber daya alam dan persaingan power menjadi permasalahan utama dalam sengketa di Laut Cina Selatan meskipun isu ini memiliki banyak faktor lain yang menjadi pemicu peningkatan dan penurunan konfliknya. Namun menurutnya, terdapat tiga komponen utama geopolitik yang mempengaruhi permasalahan tersebut yaitu masalah kedaulatan, potensi sumber daya alam serta distribusi power. Permasalahan kedaulatan sangat berpengaruh bagi Cina dan Vietnam karena menjadi "gengsi" internasional sebagai negara yang berdaulat. Sedangkan sumber daya alam menjadi alasan kepentingan ekonomi bagi kedua negara tersebut untuk mendapatkan keuntungan sebanyakbanyaknya dari ketersediaan sumber daya alam yang ada di wilayah konflik tersebut. Sedangkan distribusi power menjadi hal yang sangat penting dalam memahami pergerakan politik keamanan di kawasan, terutama perbedaan yang cukup jauh dalam hal kapabilitas pertahanan antara Vietnam dan Cina.

\section{Analisis}

Tulisan ini membahas permasalahan tersebut dari konflik kedaulatan wilayah antara klaim dari negara-negara yang terlibat seperti Vietnam dan kerjasama dalam eksploitasi oleh Vietnam yang bertikai dalam 
memberikan pencegahan terhadap perang di Laut Cina Selatan. Pembahasan pertama adalah mengenai klaim kedaulatan dari negaranegara yang terlibat dalam konflik tersebut dan penggunaan militer dalam pengamanan sebagai tanda keseriusan negara dalam menjaga wilayah kedaulatannya. Pembahasan berikutnya adalah kerjasama negara yang bertikai yaitu Cina dan Vietnam dalam pengembangan eksploitasi sumberdaya yang ada di wilayah konflik, terutama dalam hal minyak bumi dan gas alam. Bagian terakhir adalah hubungan antara klaim kedaulatan dan kerjasama oleh negara yang berkonflik dapat mencegah perluasan konflik dari klaim kedaulatan menjadi perang.

\section{Militer dalam Konflik Kedaulatan}

Menurut Buszynski dan Sazlan mengenai sejarah dari klaim Cina di Laut Cina Selatan adalah melalui sejarah, Cina merasa memiliki hak atas wilayah tersebut jauh sebelum negara-negara baru di sekitar wilayah tersebut memiliki kedaulatan (Buszynski \& Sazlan, 2007). Poin kunci tentang klaim maritim oleh Cina adalah bahwa pandangan mereka menurut Konvensi Konvensional PBB tentang Hukum Laut (UNCLOS) akan menghilangkan apa yang dianggap Cina sebagai hak historisnya atas Laut Cina Selatan dan memberikan negara-negara pesisir kontrol atas sumber daya yang Cina rasa mereka memiliki hak untuk akses. Masalah ini muncul sebagian besar karena Cina terhalangi oleh berbagai peristiwa untuk merealisasikan klaim historisnya di Laut Cina Selatan. Sementara itu, negara-negara ASEAN mengambil kesempatan untuk menduduki pulau-pulau di sana. Pembagian antara hak Cina atas hak historis dan kepemilikan yang sebenarnya atas pulau-pulau di Laut Cina Selatan adalah hasil dari Konferensi San Francisco September 1951 ketika kekuatan sekutu gagal mengidentifikasi siapa yang memiliki hak atas pulau-pulau Laut Cina Selatan ketika mereka mendivestasi kepemilikan Jepang. 
Cina telah melakukan tindakan nyata dalam pemasangan fasilitas militer dan penggelaran aset militer di Laut Cina Selatan (Liang Fook \& Hoang Hop, 2018). Pada tahun 2014 Cina pertama kali memulai reklamasi tanah dan pembangunan pulau, kemudian pada tahun 2015 diperluas untuk mencakup kebutuhan untuk memberikan layanan sipil yang bermanfaat bagi negara lain dalam bentuk barang publik seperti pencarian dan penyelamatan maritim, pencegahan dan mitigasi bencana dan penelitian kelautan, pengamatan meteorologi hingga keselamatan navigasi. Pada bulan Februari 2016, Cina mengerahkan dua peluncur rudal permukaan ke udara yaitu HQ-9 serta sistem radar di Pulau Woody yang merupakan bagian dari Kepulauan Paracel. Hingga pada bulan Desember 2016, gambar satelit yang dirilis oleh Asia Maritime Transparency Initiative menunjukkan bahwa Cina telah memasang peralatan dalam bentuk senjata anti pesawat besar dan kemungkinan sistem senjata jarak dekat di masing-masing dari tujuh pos terdepan di Laut Cina Selatan.

Dalam merespon tindakan Cina tersebut, Vietnam memperkuat ikatan pertahanan dan kemitraannya dengan kekuatan asing seperti Amerika Serikat, Australia, Jepang dan India sebagai bentuk respon dari tindakan Cina di Laut Cina Selatan(Liang Fook \& Hoang Hop, 2018). Pada bulan Oktober 2016, USS Frank Cable dan USS John S. McCain menjadi kapal perang AS pertama yang ditugaskan untuk berlabuh di Pelabuhan Internasional Cam Ranh sejak berakhirnya Perang Vietnam pada tahun 1975. Pada bulan Maret 2018 ketika USS Carl Vinson tiba di Danang, dan menjadikan USS Carl Vinson sebagai kapal induk pertama Amerika yang berlabuh di Vietnam sejak 1975. Amerika Serikat juga mengirim enam kapal patroli ke penjaga pantai ke Vietnam untuk mendukung Vietnam.

Ketegangan konflik di Laut Cina Selatan semakin tinggi dengan keterlibatan militer tersebut, namun arah konflik tersebut belum mengarah pada konflik terbuka maupun perang. Meskipun konflik di Laut 
Cina Selatan semakin tinggi intensitasnya, namun kerjasama diantara negara yang terlibat konflik masih bisa terealisasikan. Kerjasama yang antara Cina dan Vietnam misalnya dalam mengeksploitasi sumber daya minyak bumi dan gas alam masih bisa tercapai, misalnya saja Ketika presiden Vietnam Tran Due Luong mengunjungi Beijing pada Juli 2005, Cina dan Vietnam menekankan kerja sama dalam eksplorasi minyak dan gas alam di Laut Cina Selatan dan keinginan mereka untuk mengubah perbatasan mereka menjadi salah satu perdamaian, persahabatan dan stabilitas jangka panjang (Buszynski \& Sazlan, 2007).

Peningkatan kapabilitas power di wilayah Laut Cina Selatan belum mampu mengarah pada konflik dikarenakan masih ada bentuk kerjasama. Dengan membagi potensi sumberdaya yang ada di wilayah Laut Cina selatan, melalui kerjasama menciptakan penurunan tensi ketegangan konflik. meskipun ketegangan batas wilayah masih menjadi permasalahan utama konflik, sumberdaya juga menjadi bagian penting. Karena penyelesaian batas wilayah selalu memakan waktu yang lama dalam penyelesaiannya, penting untuk negara-negara yang mengklaim wilayah laut Cina Selatan untuk tetap memanfaatkan dan mengelola sumberdaya yang ada di wilayah tersebut.

\section{Kerjasama Vietnam dan Cina}

Setelah kunjungan kerjasama antara Cina dan Vietnam di Beijing, Wakil Presiden Cina Zeng Qinghong menyatakan pada Oktober 2005 bahwa Cina siap untuk mencapai kesepakatan dengan Vietnam mengenai perbatasan darat dan untuk secara aktif mendorong maju eksplorasi bersama daerah-daerah yang disengketakan di Laut Cina Selatan. Pemimpin Partai Vietnam Nong Due Manh merespon hal tersebut dengan mengunjungi Beijing pada Agustus 2006 dan menyetujui eksplorasi minyak bersama dengan Cina di Teluk Tonkin / Beibu (Buszynski \& Sazlan, 2007). 
Bahkan jauh sebelum itu, Cina telah memprioritaskan hubungan baik dengan negara tetangganya, dengan membatalkan proyek mengenai kerjasama dalam eksplorasi kekayaan minyak dan gas di Laut Cina Selatan. Setelah protes Vietnam pada tahun 1994, Cina National Offshore Oil Corporation (CNOOC) membatalkan proyek eksplorasi bersama dengan perusahaan AS Crestone Energy di dekat kepulauan Spratly (Stirring up the South China Sea (IV): Oil in Troubled Waters, 2016). Hal ini membuktikan bahwa di balik konflik yang terjadi di wilayah Laut Cina Selatan, masih terdapat peluang untuk membangun kepercayaan dalam bekerjasama untuk mencapai kepentingan mereka. Bahkan hal tersebut mampu mencegah dan mengesampingkan permasalahan dengan menggunakan militer militer.

Penguasaan sumber daya alam secara sepihak juga hanya akan mempersulit keadaan di wilayah konflik. Oleh karena itu, tindakan Cina dalam membangun kerjasama eksploitasi sumberdaya alam dengan Vietnam dapat menjadi usaha pendekatan dalam mengurangi tensi konflik di wilayah Laut Cina Selatan. Jika permasalahan kedaulatan dan batas wilayah tidak dapat ditawar lagi, maka kerjasama ekonomi pada wilayah perbatasan dapat menjadi peluang besar dalam menghindari konflik terbuka yang hanya akan merugikan kedua belah pihak serta memperburuk kondisi ekonomi kawasan.

Tindakan Cina dan Vietnam dalam membangun kerjasama eksploitasi sumber daya alam di wilayah Laut Cina Selatan dapat juga kita pahami sebagai pemanfaat Cina agar tidak merusak hubungannya dengan ASEAN terutama dalam hal kerjasama serta ekonomi. Dalam situasi seperti ini, tindakan agresif militer Cina melalui konflik terbuka hanya akan merugikan posisinya di kawasan sebagai musuh bersama. Namun melalui kerjasama tersebut, Cina mampu menunjukan dirinya sebagai negara yang tidak agresif dan militeristik. Sedangkan bagi Vietnam hal tersebut menjadi kesempatan untuk menghindari konflik 
terbuka dengan salah satu rising power yang hanya akan menimbulkan kerugian. selain itu, kerjasama tersebut membuktikan kehadiran Vietnam sebagai negara yang mampu duduk setara dengan Cina dalam permasalahan Laut Cina Selatan.

Kerjasama tersebut juga memberikan waktu untuk melakukan distribusi power. Cina dan Vietnam memiliki kesempatan untuk memperkuat power mereka dan mempersiapkan jika nanti konflik terbuka tidak dapat dihindari lagi. Namun selain itu juga, momen kerjasama dapat menjadi jeda untuk kawasan agar negara-negara lain baik yang terlibat dalam sengketa Laut Cina selatan maupun yang ada di dekat Cina dan Vietnam tidak merasa terancam atas persaingan mereka.

\section{Distribusi Power}

Perbedaan kapabilitas power antara Cina dan negara-negara pengklaim lainnya di Laut Cina Selatan memang cukup jauh. Namun bagi Cina, penggunaan konflik terbuka hanya akan menguntungkan ASEAN dan negara klaim lainnya. Hal tersebut dikarenakan pengaruh ASEAN yang besar di wilayah Laut Cina Selatan. Dengan melakukan serangan terbuka di wilayah Laut Cina Selatan, Cina hanya akan diberikan label sebagai negara penjajah dan menjadikan ASEAN sebagai aktor protagonis yang akan melakukan distribusi power dengan merangkul aktor-aktor internasional lainnya (Emmers, 2010).

Alasan yang lain adalah karena ASEAN merupakan salah satu mitra dagang terbesar Republik Rakyat Cina. Kebijakan persaingan telah membawa perubahan dalam keunggulan komparatif dinamis antara ASEAN dan Cina yang bersaing dengan pengaruh Jepang (Saputra, 2017). Pada tahun 2019, terdapat empat negara ASEAN dalam peringkat 15 besar mitra dagang Republik Rakyat Cina. Keempat negara itu adalah Vietnam peringkat ke 5, Singapura peringkat ke 10, Malaysia peringkat ke 13, dan Thailand peringkat ke 15 (Workman D, 2020). Dengan data 
tersebut, jika memutuskan untuk berperang dengan negara-negara Asia Tenggara yang bersengketa dengannya, besar kemungkinan akan membuat negara-negara Asia Tenggara lain ikut membantu sesama “rekan Asia Tenggara"-nya. Hal ini akan membuat Republik Rakyat Cina kehilangan mitra dagang strategis yang akan berpengaruh pada perekonomian Republik Rakyat Cina, padahal Republik Rakyat Cina merupakan negara konsumen energi terbesar di dunia.

Sebagai konsumen energi terbesar di dunia, Republik Rakyat Cina akan membutuhkan lebih banyak energi di tahun-tahun mendatang untuk mempertahankan urbanisasi dan industrialisasi yang sedang berkembang (Sagatom Saha \& Quinn Marschik, 2016). Fenomena urbanisasi dan ekonomi Cina yang berkembang pesat membuat konsumsi energinya akan meningkat hampir lima puluh persen hingga tahun 2035, dimana konsumsi energi ini mencakup seperempat dari konsumsi global (Sagatom Saha \& Quinn Marschik, 2016). Sebagai salah satu latar belakang agresivitas Republik Rakyat Cina di Laut Cina Selatan adalah untuk memenuhi kebutuhan energi tersebut. Pada saat ini, 86 persen impor minyak dan gas yang dilakukan Republik Rakyat Cina harus melewati Laut Cina Selatan (Sagatom Saha \& Quinn Marschik, 2016). Jika perang meletus di Laut Cina Selatan, maka ketersediaan energi untuk memenuhi kebutuhan domestik Republik Rakyat Cina akan tersendat dan berpengaruh pada ekonomi negara secara keseluruhan.

Kemudian alasan lainnya adalah tradisi just war yang dipegang teguh Cina dalam mengelola kebijakan luar negerinya mengenai perang (Godehardt N, 2008). Cina tidak akan melakukan perang jika itu bukan untuk melindungi dirinya dari ancaman luar atau hanya akan berperang jika Cina diserang. Selain itu, Republik Rakyat Cina masih menganggap Amerika Serikat sebagai hegemoni global dengan kekuatan militer terkuat di dunia. Perang di Laut Cina Selatan akan menyulut intervensi Amerika Serikat ketika sekutu-sekutunya di Asia Tenggara diserang. Hal ini 
disebabkan oleh karena kepentingan ekonomi dan politik Amerika Serikat di Asia Tenggara yang akan terancam jika konflik di Laut Cina Selatan berujung pada konfrontasi militer terbuka (Farley R, 2018). Bagi Republik Rakyat Cina sendiri, perang dengan Amerika Serikat sama dengan berperang dengan mitra dagang nomor satunya (Workman D, 2020). Hal tersebut akan membuat ketersediaan energi dan ekonomi Republik Rakyat Cina akan kolaps.

Logika tersebut juga berlaku terhadap Vietnam jika melakukan konflik terbuka dan langsung berhadapan dengan Cina. Meskipun Vietnam melakukan distribusi power dengan negara super power seperti Amerika Serikat misalnya, konflik terbuka tidak akan mempermudah Vietnam dalam memenangkan klaimnya terhadap wilayah di Laut Cina Selatan. Sebaliknya, tindakan tersebut akan memberikan justifikasi terhadap Cina untuk melakukan serangan balasan dan mempertegas posisinya sebagai rising power di Asia.

Sebaliknya dengan melakukan kerjasama dalam hal eksploitasi kekayaan alam yang ada di wilayah Laut Cina Selatan, maka semua pihak yang berkonflik dapat mempersiapkan distribusi powernya tanpa menguntungkan pihak lawan. Selain itu, ekonomi politik kawasan akan cenderung stabil serta kedua belah pihak memiliki kesempatan yang sama dalam memperhitungkan kelayakan sumberdaya yang diperebutkan di wilayah tersebut. Distribusi power sangat berkaitan dengan konflik dan ancaman kedaulatan sebagai respon dari keamanan internasional atau ancaman eksistensi suatu negara sehingga distribusi power akan mempengaruhi posisi tawar sebuah negara.

\section{Kesimpulan}

Dari pembahasan uraian tersebut, kerjasama antara negara yang terlibat konflik di Laut Cina Selatan terutama Cina dan Vietnam dapat 
mengurangi potensi perang terbuka antara keduanya. Kerjasama antara pihak yang terlibat konflik perbatasan seperti di Laut Cina Selatan dapat membuka jalur komunikasi antara pihak-pihak yang bertikai. Dengan terbukanya jalur komunikasi diantara pihak-pihak tersebut akan membuka peluang untuk mengurangi presepsi yang salah antara pihak yang terlibat. Karena perang hanya di akibatkan oleh presepsi yang salah di antara pihak yang terlibat. Oleh karena itu, penting bagi pihak yang terlibat konflik untuk saling membuka komunikasi.

Selain itu, konflik terbuka di wilayah sengketa Laut Cina Selatan hanya akan membawa pengaruh buruk terhadap stabilitas kawasan serta bagi negara yang memulainya. Memulai konflik terbuka dalam konflik antara Cina dan Vietnam di Laut Cina Selatan akan berdampak pada arah geopolitik kawasan. Bagi Cina, konflik terbuka hanya akan mengancam dan memperburuk posisinya di kawasan karena akan menjadi musuh bersama yang dikelilingi oleh negara-negara yang berpotensi menjadi musuh. Sedangkan bagi Vietnam, konflik terbuka hanya akan memperburuk konflik di Laut Cina Selatan dan akan semakin menyeret banyak aktor dalam permasalahan tersebut.

\section{DAFTAR PUSTAKA}

Buszynski, L., \& Sazlan, I. (2007). Maritime Claims and Energy Cooperation in the South China Sea. Contemporary Southeast Asia, 29(1), 143-171. https:// doi.org/10.1355/cs29-lg

Cina kembali tegaskan klaim atas wilayah di Laut Cina Selatan, (2016). Retrieved from https://www.bbc.com/indonesia/dunia/2016/07/160712_dunia_rea ksi_lautcinaselatan

Farley R, (2018). War in the South China Sea: 3 Ways America and China Fight it Out. from https:/ / nationalinterest.org/blog/buzz/war-south-china-sea-3-waysamerica-and-china-fight-it-out-32482. 
Godehardt N, (2008). The Chinese Meaning of Just War and Its Impact on the Foreign Policy of the People's Republic of China. Retrieved from https://core.ac.uk/download/pdf/6862967.pdf.

Hai Dang Vu (2013) A Bilateral Network of Marine Protected Areas Between Vietnam and China: An Alternative to the Chinese Unilateral Fishing Ban in the South China Sea?, Ocean Development \& International Law, 44:2, 145-169, DOI: 10.1080/00908320.2013.750984

Klaudia Malczewska. (n.d.). Chinese Claim to the South China Sea under International Law. Retrieved from http://www.un.org/depts/los/conven-

Liang Fook, L., \& Hoang Hop, H. (2018). Vietnam's Responses to China's Maritime Assertiveness in the South China Sea. Retrieved from https://www.iseas.edu.sg/images/pdf/ISEAS_Perspective_2018_50@, 50.pdf

Lumbanrau R.E, (2016). Indonesia dan China di Pusaran Laut China Selatan. Retrieved from https://www.cnnindonesia.com/nasional/20160624092606-75140606/indonesia-dan-china-di-pusaran-laut-china-selatan

Mangkuto W.S, (2020). Bukan Cuma RI, Laut Malaysia s/d Vietnam Juga diklaim China. from https://www.cnbcindonesia.com/news/20200107085224-4128148 / bukan-cuma-ri-laut-malaysia-s-d-vietnam-juga-diklaimchina

Nguyen Hong Thao (2001) Vietnam and the Code of Conduct for the South China Sea, Ocean Development \& International Law, 32:2, 105-130, DOI: $10.1080 / 00908320151100244$

Prawira, M. R. (2019). SOUTH CHINA SEA DISPUTE. Jurnal Dinamika Global, 3(02), 35-54. https://doi.org/https://doi.org/10.36859/jdg.v3i02.75

Purwantoro, yehuda. (2020). BANDWAGONING BRUNEI DARUSSALAM TERHADAP REPUBLIK RAKYAT CINA PADA TAHUN 2018 DALAM KONFLIK LAUT CINA SELATAN. Indonesian Journal of International Relations, 4(1), 1-24.

Ralf Emmers (2010) Geopolitics and Maritime Territorial Disputes in East Asia. New York. Routledge.

Ramses Amer (2014) China, Vietnam, and the South China Sea: Disputes and Dispute Management, Ocean Development \& International Law, 45:1, 17-40, DOI: 10.1080/00908320.2013.839160 
Sagatom Saha \& Quinn Marschik, (2016). Energy Demands Increasingly Shape China's Behavior in the South China Sea. Retrieved from https://www.worldpoliticsreview.com/articles/20573/energy-

demands-increasingly-shape-china-s-behavior-in-the-south-chinasea?utm_source $=$ Active + Subscribers $\& u t m \_c a m p a i g n=824 a 5 c 7 d 6 b-$ EMAIL_CAMPAIGN_2018_09_04_01_32\&utm_medium=email\&utm_ter $\mathrm{m}=0 \_35 \mathrm{c} 49 \mathrm{cbd} 51-824 \mathrm{a} 5 \mathrm{c} 7 \mathrm{~d} 6 \mathrm{~b}-$ 64267425\&mc_cid=824a5c7d6b\&mc_eid=5583f96a8f

Saputra, M. D. H. (2017). ECONOMIC RELATIONS OF ASEAN (INDONESIA) + CHINA AFTER AIIB. Jurnal Dinamika Global, 2(01), 1 - 22. https://doi.org/https://doi.org/10.36859/jdg.v2i01.30

Stirring up the South China Sea (IV): Oil in Troubled Waters. (2016). Retrieved from https://www.files.ethz.ch/isn/195791/South china sea4.pdf

Tomotaka Shoji (2011) Vietnam, ASEAN, and the South China Sea: Unity or Diverseness?, Retrieved from http://www.nids.mod.go.jp/english/publication/kiyo/pdf/2012/bull etin_e2012_2.pdf

Workman D, (2020). China's Top Trading Partners. Retrieved from http://www.worldstopexports.com/chinas-top-import-partners / 